\title{
DOCUMENTOS ARCEBISPAIS NO TOMBO H DA CATEDRAL DE SANTIAGO: GÓMEZ MANRIQUE E LOPO DE MENDOZA
}

\author{
Por
}

ALEXANDRA CABANA OUTEIRO

\section{RESUMEN}

No Tombo H da Catedral de Santiago de Compostela, libro rexistro elaborado polo notario Afonso Eanes Jacob, recóllese documentación do cabido compostelán entre os anos 1391 e 1409, incluíndo tamén traslados de documentos anteriores. Neste artigo faise unha edición de cinco documentos emitidos polos arcebispos Gómez Manrique (1351-1362) e Lope de Mendoza (1399-1445), que se insiren neste libro, achegándose tamén unha nota introductoria.

\section{PALABRAS CLAVE}

Santiago de Compostela, s. XIV, s. XV, Tombo H, fontes documentais, rexistro notarial, Afonso Eanes Jacob, notariado, arcebispo de Santiago, Gómez Manrique, Lope de Mendoza, bispo de Mondoñedo.

«CUADERNOS DE ESTUDIOS GALLEGOS», Tomo L, Fascículo 116, Santiago 2003. 


\begin{abstract}
The cartulary H of Santiago de Compostela's Cathedral -register book compiled by notary Afonso Eanes Jacob-contains documents of the chapter of Compostela dated 1391 to 1409 and includes copies of earlier documents. In this paper, the edition of five documents issued by archbishops Gómez Manrique (1351-1362) and Lope de Mendoza (1399$1445)$ and contained in this book is proposed. An introductory note is also included.
\end{abstract}

\title{
KEYWORDS
}

Santiago de Compostela, 14th Century, 15th Century, Afonso Eanes Jacob, Cartulary H, Documentary Sources, Notaries, Gómez Manrique, Lope de Mendoza, Bishop of Mondoñedo.

Os documentos que de seguido se presentan están recollidos no tombo $\mathrm{H}$ da catedral de Santiago de Compostela. Este é un libro rexistro elaborado polo notario público Afonso Eanes Jacob que contén documentación do cabido da Sé compostelana dos anos comprendidos entre 139.1 e 1409, se ben inclúe algún traslado de documentos anteriores a estas datas, un dos cales, de 1353, está incluído nesta selección.

Este tipo de documentos a miúdo están inseridos noutros ós que serven de apoio; nestes casos optei por editar tamén estes documentos-matriz para nos decatar mellor da utilidade dos traslados e da súa relación co Tombo H.

A intención desta selección é publicar nun único corpo os documentos emanados do arcebispo que recolle o libro rexistro. Tres son as figuras arcebispais que aparecen no Tombo $\mathrm{H}$ como emisores de documentos: Gómez Manrique (1351-1360), Xoán García Manrique (1383-1398) e Lopo de Mendoza (1399-1445). O que ten máis documentación no Tombo é Xoán García Manrique, cuxo mandato coincide con varios anos da súa elaboración, e logo Lopo de Mendoza, que tamén coincide no seu goberno coa redacción Tombo H: do primeiro son quince os documentos,

«CUADERNOS DE ESTUDIOS GALLEGOS», Tomo L, Fascículo 116, Santiago 2003. 
e do segundo catro, mentras que de Gómez Manrique só temos un. Dada a cantidade de documentos de Xoán García Manrique estes foron xa publicados aparte ${ }^{1}$, polo que agora presentamos conxuntamente os de Gómez Manrique e Lopo de Mendoza.

Gómez Manrique, que xa fora bispo de Palencia, foi arcebispo de Santiago de 1351 a 1362 . Pertencentía á grande familia palentina dos Manriques de Lara, unha das máis ilustres e poderosas de Castela. O documento que del aparece no Tombo $\mathrm{H}$ é unha carta de confirmación de exención de impostos dos vasalos do cabido en Caldas de Reis. Este tipo de documento é un dos máis habituais dos que se trasladan no Tombo $\mathrm{H}$, pois así rexístranse privilexios que o cabido necesita que se lle volvan confirmar cos novos gobernos, dada a inestabilidade política e os conflictos cos grandes señores: deste xeito os arcebispos Xoán García Manrique e Lopo de Mendoza asinan varios, e tamén o rei Xoán II. Don Gómez Manrique gobernou a diocese de Santiago ata 1362, ano en que foi promovido polo rei para a sé primada de Toledo.

O sevillano Lopo de Mendoza substituíu no arcebispado de Compostela ó exiliado Xoán García Manrique, sobriño de don Gómez, no ano 1399 como administrador da diocese, continuando ó mesmo tempo como bispo de Mondoñedo, e xa no 1400 co cargo de arcebispo. A pesar do moito que intentou ser promovido a Toledo ou trasladado á súa Sevilla natal, nunca o conseguiu, e o seu longo pontificado só rematou coa súa morte no ano 1145.

É de notar que o documento emitido polo palentino Gómez Manrique está en galego, así como tamén os dous primeiros, un como administrador e outro xa como arcebispo, de Lopo de Mendoza. Sen embargo, os dous últimos deste, varios anos posteriores, están en castelán, sinal probable -aínda que o estudio escapa dos límites deste traballo- de que don Lopo de Mendoza tendeu a formar unha curia de xentes do seu país, incluído o notario. Este cambio de notaría aparece precisamente reflectido no documento do 1404. Agora ben, neste mesmo tombo, cando as palabras orais do bispo son recollidas por un notario galego, aparecen transcritas na nosa lingua, o cal, por suposto, non quere dicir que nesas ocasións falase en galego, senón que esta era a lingua instrumental natural do notario.

\footnotetext{
${ }^{1}$ CABANA OUTEIRO, Alexandra, «Documentos do arcebispo Xoán García Manrique no tombo $\mathrm{H}$ da catedral de Santiago» en A Trabe de Ouro, ${ }^{\circ}$ 46, abril-maio-xuño, 2001, pp. 241-257.
}

«CUADERNOS DE ESTUDIOS GALLEGOS», Tomo L, Fascículo 116, Santiago 2003. 
1397 , setembro, 2

Santiago

Traslado dunha carta (30-I-1353) do arcebispo don Gomes Manrique na que lles ordena ós oficiais de todo o seu arcebispado que non lle cobren "peito" ós caseiros do cabido na vila de Caldas de Reis, despois de ter feito pesquisa sobre a verdade deste privilexio.

Santiago, Arquivo da Catedral, Tombo H, folio 6 r., inverso.

${ }^{2}$ Era de 1391.

Año de 1353. Mandato del Arcobispo [sic $]^{3}$ don Gómez en fauor de los caseros del cauildo en Caldas.

${ }^{4}$ Nota

Don Gomes, por la graça de Deus e da santa iglleia de Roma, arçibispo de [Santiago], [capelán $]^{5}[\mathrm{~m}$ ] ayor del rey e chançeller e notario mayor do rregno de Leóm, aos [pertegeiros de?] [... $]^{6}[\ldots]^{7}$ mos de terra de Salnés e a tódoslos outros ofiçiães de todo o noso arçibispado e a cada hũu de uós a que esta nosa carta for mostrada, soúde. Sabede que $\mathrm{p}[\ldots]^{8}$ ontre Lopo Afonso, arçidiago de Mayorga e cóengo de Santiago, por Fernán [... ${ }^{9} d a$ hũa] parte e Johán Fernández, procurador do noso conçello da nosa villa de Caldas, $\mathrm{d}[\text { a outra parte } . . .]^{10}$, rasón que desj́a o dito arçidiago que como el teuesse porlo cabidoo da igleia de [Santiago... ${ }^{11}$ ] en Follente Johán Afonso, Pero Fariña e Johán da Ribeira e Johán Myço e Esteuõo do

\footnotetext{
${ }^{2}$ Marxe superior, letra do século XVIII.

${ }^{3}$ Uso estes [ ] para marcar texto ilexible, espacios en branco ou anotación miñas.

${ }^{4}$ Marxe superior esquerda, mesma letra que o documento.

${ }^{5}$ Palabra borrada co tempo, recupéroa por comparación con outros textos.

${ }^{6}$ Unha palabra ilexible.

${ }^{7}$ Parte da palabra ilexible.

8 +-Vintecinco caracteres ilexibles, pois está borrado e falta incluso un anaco de pergameo.

$9+$ - vintecinco caracteres ilexibles.

10 +- vintecinco caracteres ilexibles.

${ }^{11}+$ - vinte caracteres ilexibles.
}

«CUADERNOS DE ESTUDIOS GALLEGOS», Tomo L, Fascículo 116, Santiago 2003. 
Outeiro [seus seuentes?] e nunca pagasen moeda nen peytan ninhũa, que agora nouamente o dito conçello [...peyte?] $]^{12}$ en moeda e en peita o que desja que nunca pagaran depois que foran do dito cabidoo. E o dito Johán Fernandes procurador do dito conçello diso que sy. E nós para sabéremos a verdade deste feito preguntamos ao procurador do dito arçidiagado se podía prouar esto que desja e el diso que sy. E nós para esto lle asinamos térmjno ao qual térmjno os ditos procuradores apareçeron ante nós. $\mathrm{E}$ entón o dito Fernand Eanes, procurador do dito arçidiago, dounos hũa pesquisa carrada [sic] e seẽllada con dous seẽllos que fora ẽna dita villa de Caldas, a qual pesquisa nós mandamos tirar e enquerer sobr'esta rasón e vimos a dita pesquisa de veruo a veruo toda deligentemente. E porla dita pesquisa achamos presente o dito procurador do dito conçello achamos porla dita pesquisa que aqueles que moran ẽnos casares da iglleia do cabidoo da igleja de Santiago que non deue $<n>{ }^{13}$ peitar peyto nihôu. E mandamos a uós e a cada hôu de vós en vertude d'obidiençia e so pena d'escomeyón e de cen moravedís da bõa moeda. E dos ofiçios que teedes que d'aquí endeante non consintades ${ }^{14}$ a njnhôu que leue nen tire pedido nen peito ninhôu nen os poña en eles en todos aqueles que moraren ẽnas casas do dito cabidoo e lavraren as súas herdades, segundo que dito hé do dito arçidiago ${ }^{15}$, e non consintades a ninhôu que lle sobr'ello faça força nen desagido sobr'esta rrasón. E os hôus nen os outros non ffaçades so a dita pena sobredita. Dada ẽna nosa villa de Noya, era de mjll e tresentos e noueenta e hôu anos, trijnta días de janeiro. Cometius archiepiscopus conpostellanus. Fernán Peres, notario por mandado do arçibispo.

Feita por Rodrigo Garçía.

Ano da naçença de noso señor Jhesu Christo de mill e tresentos e noueenta e sete anos, dous días do mes de setenbro: Foy dada a autoridade a esta ${ }^{16}$ carta por Johán Martíns de Monrayal, juíz de Vellestro ordenario ẽna iglleja de Santiago, a qual era scripta en papel e firmada do nome do dito señor arçibispo e do nome de Fernán Peres, notario, e seellada en

\footnotetext{
$12+$ - doce caracteres ilexibles.

${ }^{13}$ Uso estes $<>$ para incluír letras ou palabras esquecidas por quen escribe o documento.

${ }^{14}$ Riscado: que.

${ }^{15}$ Riscado: do.

${ }^{16}$ Riscado un caracter ilexible.
}

«CUADERNOS DE ESTUDIOS GALLEGOS», Tomo L, Fascículo 116, Santiago 2003. 
costa do sẽello pontefical do dito señor arçibispo segundo por ela paresçía. A qual carta eu Afonso Eanes Jacob, notario, etcétera vin etcétera. Testemoias: Johán Peres, meestrescolla de Santiago, Garçía Suares, notario, Lopo Afonso, scriuán, e outros.

Traslado dun alvalá (25-IX-1399) do bispo de Mondoñedo e administrador de Santiago, Lopo de Mendoza, no que lles manda ós que cobran os décimos do porto de Pontevedra que llelos paguen ó cabido de Santiago.

Santiago, Arquivo da Catedral, Tombo $\mathrm{H}$, folio 6v, inverso.

Mencionado por LÓPEZ FERREIRO, Antonio, Historia de la Santa A.M. Iglesia de Santiago de Compostela, tomo VII, p. 8.

Nós o bispo de Mondoñedo, admijstrador da igleja e arçibispado de Santiago, oydor ẽna audiençia de noso señor el rey, fasemos saber a vós Johán Nunes da Ponte e Johán Gonçalves, fiẽes dos désemos do porto da nosa villa de Ponteuedra da parte que perteêçe a noso señor el rey, que o dayán e cabidõo desta nosa igleja nos feseron çerto em como han de auer en cada hũu ano nos ditos désemos mill libras para pam de cada día e por o que fórades requeridos da súa parte que llas pagásedes este ano que o non quiserdes faser disendo que uos mandaramos põer en eles enbargo. Por que uos mandamos que logo visto este alualá dedes et pagedes ao procurador dos ditos deán e cabidõo as ditas mjll libras que han de auer nos ditos désemos segundo dito he. Et non o leixedes de faser por rasón $[o u]^{17}$ enbargo que vos en eles da nosa parte foy posto, ca nos alçamos o dito enbargo en quanto tange a esta contía. Et non $[f]^{18}$ açades ende al sopena da nossa merçet e de mill moravedís para a nosa cámara. Feita

\footnotetext{
${ }^{17}$ Está roto o pergameo.

${ }^{18}$ Está roto o pergameo.
}

«CUADERNOS DE ESTUDIOS GALLEGOS», Tomo L, Fascículo 116, Santiago 2003. 
vijnte e çinquo días de setenbro, anno dominj $\mathrm{M}^{\circ} \mathrm{CCC}^{\circ} \mathrm{XC}^{\circ}$ nono. Episcopus et administrator.

Concertado porlo original scripto en papel e firmado do nome do dito bispo e admijstrador.

Traslado dun alvalá (8-III-1400) do arcebispo de Santiago Lopo de Mendoza no que lles manda a varios señores leigos que non lles cobren impostos ós labregos do cabido.

Santiago, Arquivo da Catedral, Tombo H, folio 5r, inverso.

Mencionado por LÓPEZ FERREIRO, Antonio, Historia de la Santa..., tomo VII, p. 8 e 97.

${ }^{19}$ Sobre la libertad delos caseros de la Yglesia

${ }^{20}$ Goncalo Prego de Montaos fue señor de la cassa de Montaos. Juan Martínez d'Isorna, padre o tío del señor arcobispo don Álbaro de Ysorna, señor de la cassa de Rodeiro y Canba. Bernardo Yánez do Canpo señor de la cassa de O Canpo. Goncalo Zores de Ulloa F. de la Reportería acendiente de los condes de Monterrey. Juan Barela de Dubra señor de la cassa de Dubra [unió?] esposada en la de Montaos. Año de 1400.

Dom Loppo porla graça de Deus arçibispo de Santiago, capellán mayor de noso señor el rey e sseu notario mayor do regno de León, a uós Garçía Prego de Montaos, caualleiro, Johán Nunes d'Issorna, Bernaldo Eanes do Canpo, Gonçalvo Ossores d'Ulloa, Johán Varela de Duura et a tódoslos outros colledores em renda ou en fieldade ou em outra maneira qual quer dos enpréstidos de nosso señor el rey en todo ${ }^{21} \mathrm{o}$ noso arçibispado et a

\footnotetext{
${ }^{19}$ Marxe superior, letra do s. XVIII.

${ }^{20}$ Marxe esquerda, letra do s. XVIII

${ }^{21}$ Riscado: s.
}

«CUADERNOS DE ESTUDIOS GALLEGOS», Tomo L, Fascículo 116, Santiago 2003. 
cada hũu de uós, soúde. Sabede que o dayán e cabidõo da nossa igleia de Santiago se nos enviaron querelar et dizer que os seus caseyros, seruiçães, lauradores que lauran as súas herdades e moran ẽnas súas cassas ẽnos seus coutos e préstamos e tẽenças e jglijarios, que foron e son liures e quitos e exssentos por priujlegios liberdades dos reys de Castella e de León, et confirmadas por noso señor el rey don Enrrique que Deus manteña, de toda maneira de moeda e ffossadeyra e peyta jnpréstido e doutro tributo qualquer ou quaesquer. Et que esto que les fora senpre moy ben agardado et que agora nouamente que uós e algũus de uós e vossos colledores que por uos collen e recadan os enpréstidos ẽnas terras chãas ge los penorades e fazer penorar e aos ditos seus caseyros, seruiçaes e lauradores que assí moran ẽnas ditas terras en que uós e cada hũus de uós colledes e fazedes coller os ditos enpréstidos, et en esto que les quebratauades seus priuilegios e liberdades et que reçebían en elo grande agraueo. Et pidíronnos sobr'elo merçẽe, por que nós dizemos e mandamos en vertude de santa obidiençia e so pena d'escomoyón e da nossa merçẽe que non demandedes nen mandedes demandar aos seus homes, lauradores e seruiçães e casseyros que moran ẽnas súas herdades e lauran as súas herdades das súas tẽenças e préstamos iglijarios os ditos enpréstidos, nen nos mandedes logo entregar, ca assí he nossa merçẽe. Et non façades ende al. Dada ẽna nossa villa de Pontevedra, oyto días de março ano do nasçemento de noso señor Ihesu Christo de mjll e quatroçentos anos. Archiepiscopus conpostelanus. 
s.d.

Santiago

Traslado dunha carta revocatoria (6-V-1404) do arcebispo de Santiago Lopo de Mendoza pola que lle retira a condición de notario do arcebispado a Johán de Padrón, pois lles facía competencia dentro da cidade de Santiago a outros notarios públicos.

Santiago, Arquivo da Catedral, Tombo $\mathrm{H}$, folio 6v., inverso.

Citado por LÓPEZ FERREIRO, Antonio, Historia de la Santa..., tomo VII, p. 10.

${ }^{22}$ Auer [?]

Nós el arçobispo de Santiago, capellán mayor de nuestro señor el rey et su notario mayor del reyno de León et oydor de la su abdiençia, por rrazón que a nós es dicho et fecho entender que Iohán de Padrón, scripuano de la abdiençia de la nuestra igllesia de Santiago, se estendía et faze asentamjento público em dar et signar scripturas públicas dentro en la nuestra çibdat de Santiago como non deuja em grante perjudiçio de los notarios de la dicha nuestra çibdat a ynstançia de vna carta que lle aujamos dado para em todo nuestro arçobispado de Santiago. Por ende nós, considerando que vsando el dicho Iohán de Padrón de lla dicha scripuanja, signando así como notario público dentro en la dicha nuestra çibdat, que seería grante perjudiçio a llos dichos notarios de la dicha nuestra çibdat et contra los sus priuilegios et libertades, por esta nuestra carta reuocamos et damos por ninguna la dicha carta que así lle damos de la dicha notaría pública del dicho nuestro arçobispado et queremos que non uala. Et mandamos, so pena de la nuestra merçed et de dos mill maravedís para la nuestra cámara, al dicho Juan de Padrón que non vse del dicho ofiçio de scripuano público em perjudiçio de los dichos notarios nin signe cartas njn scripturas públicas por rrazón del dicho ofiçio em ninguna manera em todo el dicho arçobispado. Et por que él de todo esto non pueda pretender ygnorançia mandamos que lle sea publicada esta nuestra carta reuocatoria

${ }^{22}$ Marxe esquerda, mesma letra que o documento.

«CUADERNOS DE ESTUDIOS GALLEGOS», Tomo L, Fascículo 116, Santiago 2003. 
delante scripuano público. Dada em Ualladolid, seys días de mayo anno domini $\mathrm{M}^{\circ} \mathrm{CCCC}^{\circ}$ quarto. Archiepiscopus conppostellanus.

Concertada porlo ouriginal scripto en papel e firmada do nome do dito señor arçibispo e sẽlada en costa de seu sẽlo posto en çera uermella.

s.d.

Santiago

Traslado dun alvalá (20-XI-1406) do arcebispo de Santiago Lopo de Mendoza no cal lles prohibe ós recadadores dos impostos reais cobrárenllelos ós labregos dos coutos e herdades do cabido.

Santiago, Arquivo da Catedral, Tombo H, folio 10r-inv.

Mencionado por LÓPEZ FERREIRO, Antonio, Historia de la Santa..., tomo VII, p. 97.

${ }^{23}$ El Arçebispo don Lope a los arrendadores de los repartimientos reales, que no se comprehendan caseros de la Yglesia

${ }^{24}$ nota

Dom Lopo, porla graça de Dios et de la santa jglesia de Roma, arcobispo de Santiago, capelán mayor de nuestro señor el rey et su notario mayor del reyno de León et oydor de lla su abdiençia, a vós los recabdador o rrecabdadores o $\mathrm{co}^{25}$ jedor o $\mathrm{co}^{26}$ jedores arrendadores de llas monedas que agora noso señor el rey lançó en los sus reynos et que vós avedes de coger et recabdar en el nuestro arçebispado de Santiago et a cada vno de uós a quien esta nuestra carta fuer mostrada, salut et bendiçón. Sepades qu'el cabildo et personas de la nuestra eglesia de Santiago $\operatorname{nos}^{27}$ enviaron a dizer que vós $\backslash$ que $/{ }^{28}$ demandades a los sus lauradores et caseros que

\footnotetext{
${ }^{23}$ Marxe superior, letra do s. XIX.

${ }^{24}$ Marxe esquerda, mesma letra do documento.

${ }^{25}$ Riscado: rrej.

${ }^{26}$ Riscado: rrej.

${ }^{27} \mathrm{~N}$ está sobreposto a $\mathrm{v}$.

${ }^{28}$ Uso estes $\backslash /$ para incluír palabras que están entre liñas ou nas marxes.
} 
moran en los ssus cotos et herdades que paguen las dichas monedas et que los enprazades et prendades por ellas siendo ellos quitos et exsentos dẻ pagar las dichas monedas por priuilegios que la dicha nuestra jglesia et nós tenemos de los reys donde nuestro señor el rey desçende et confirmados por nuestro señor el rey, los quales fasta aquí fueron gardados et conplidos em todo et por todo. Por que vos mandamos a vós et a cada vnos de uós a los que sodes christianos em vertude de santa obediençia et so pena de excomonión et a los judíos sub las penas contenjdas en los dichos priujlegios et vos amonestamos para ello primo, secundo, terçio dándouos dos días por cada vna moniçión, asj que del día que vos esta nuestra carta fuer mostrada fasta seys días luego ${ }^{29}$ sigentes vós tornedes et fagades tornar a los lauradores et seruiçiales et casares del cabildo et personas benefiçiados de lla dicha nuestra jglesia que moran em sus cotos et herdades qualesquier prendas que por esta rrasón les avedes tomadas o lleuado ${ }^{30}$. Et dende em adeante non lles leuedes njn mandedes leuar d'ellos llas dichas monedas njn los enprazedes sobr'ello et que lles gardedes los ditos priuilegos $[\ldots]^{31}$ pasado el dicho térmjno em adelante, canonica moniçione premisa ponemos em vós los christianos sentençia de excomunión en estos escriptos et contra los judíos protestamos de llos sẽer demandadas las penas de los dichos ${ }^{32}$ priuilejos et sea proçidido contra ellos a las penas del dicho. Et so las dichas penas mandamos a los jujzes et alcalldes et merynos et justiçias que non prendem njn consintan prendar a los dichos labradores porlas dichas monedas pues que som exsentos por los priuillegios et por mandado de nuestro señor el rey. Dada en la nuestra villa de Caldas, veynte días de nouenbro, anno dominj $\mathrm{M}^{\circ}$ $\mathrm{CCCC}^{\mathrm{o}}$ sexto. Archiepiscopus conpostellanus.

${ }^{33}$ Este he traslado da sobredita carta do señor arçibispo scripta en papel e firmada de seu nome e sẽlada en costa de seu sẽlo posto en çera uermella segundo que por ela paresçía. A qual carta eu Afonso Eanes Iacob, notario público iurado de Santiago, vy e lij de ueruo a ueruo e aquí ben e verdadeiramente fis trasladar e meu nome e sinal poño que tal he.

\footnotetext{
${ }^{29}$ Riscado: $\mathrm{s}$.

${ }^{30}$ Riscado: s.

${ }^{31}$ Unha palabra ilexible.

${ }^{32}$ Riscado: pro.

${ }^{33}$ Riscado: concertada porlo original qual era escripta em papel e firmada do nome do dito señor arçibispo e seelada do seu seelo em costa sobre çera vermella.
}

«CUADERNOS DE ESTUDIOS GALLEGOS», Tomo L, Fascículo 116, Santiago 2003. 